\title{
Trajes carnavalescos e 0 nível de conhecimento dos foliōes em relação a proteção ultravioleta
}

\author{
Carnival costumes and the level of knowledge of revelers in relation \\ to UV protection
}

AMARAL, Wanderlayne Fernandes do Universidade Federal Rural de Pernambuco - UFRPE wanderlayne_amaral@hotmail.com

MARTINS, Etienne Amorim Albino da Silva Universidade Federal Rural de Pernambuco - UFRPE etienneaas@hotmail.com

\begin{abstract}
Resumo
Esta pesquisa teve como objetivo analisar o nível de conhecimento dos foliões quanto aos riscos à saúde provocados pela radiação ultravioleta RUV e sua influência na escolha de fantasias e vestuários para os dias de folia. A metodologia aplicada consistiu no estudo de campo proposto por Gil (2008). Evidenciou-se a ausência de preocupação por parte dos foliões, quanto a exposição excessiva à RUV, pois estes se expõem por longos períodos de tempo sem a

\section{Abstract}

This research aims to analyze the level of knowledge of revelers regarding the health risks caused by ultraviolet radiation - UVR and its influence in the choice of costumes for the carnival days. The methodology consisted of the field study proposed by Gil (2008). We evidenced the absence of concern by the revelers about the excessive exposure to the UVR, since they are exposed for long periods of time without the necessary SPF and UPF protection.
\end{abstract} proteção necessária de FPS e UPF.

Palavras chave: Exposição solar. Roupas de carnaval. Proteção UV.

Keywords: Sun exposure. Carnival clothes. UV protection. 


\section{INTRODUC̣ÃO}

Durante o carnaval brasileiro os foliões costumam estar expostos ao sol por longos períodos de tempo, podendo ocasionar conforto térmico reduzido no uso de suas fantasias. Neste sentido, utilizam-se de trajes curtos, decotados ou sobrepostos, os tecidos destes vestuários são na grande maioria de fibras manufaturadas - sintéticas - poliéster ou poliamida por estes apresentarem um custo reduzido e uma grande variedade de texturas, estruturas e cores.

Geralmente, os tecidos das fantasias e dos vestuários utilizados são desapropriados no quesito de proteção da pele, por promover alta sensação de desconforto durante os festejos, levantando o seguinte questionamento: "Até que ponto os trajes carnavalescos podem atuar como escudo de proteção ultravioleta dos foliões?".

Desta forma, considera-se a importância deste trabalho para a análise dos atuais trajes carnavalescos a fim de compreender sua atuação na proteção dos foliões durante os dias de carnaval, dando subsídios necessários para a confecção de trajes que aliem a diversão do carnaval à proteção UV.

\subsection{Carnaval: um Breve Histórico}

O carnaval chegou ao Brasil a partir do século XIII, quando os portugueses trouxeram a brincadeira que consistia em um jogo em que as pessoas sujavam umas às outras com tintas, farinha, ovos e também atiravam água (BARBOSA, 2017). O nome Carnaval vem de "carne vale", seu significado está ligado ao fato dessa festa pagã acontecer durante os quatro dias que antecedem a quaresma, um longo período de privação, portanto era como uma despedida dos pecados da carne. Esse nome surgiu depois que a celebração foi legalizada pela Igreja Católica para coibir o que a instituição classificava como celebração pecaminosa. Ou seja, a celebração tinha como objetivo principal extravasar e fazer tudo que durante a quaresma era proibido (BARBOSA, 2017).

Em Pernambuco, o carnaval diz respeito à festa de momo realizada nas cidades do Recife e de Olinda. Os primeiros sinais dos clarins de Momo no estado surgiram no século 17, quando trabalhadores das companhias carregadoras de açúcar e de mercadorias se reuniam para a Festa de Reis, formando cortejos que carregavam caixões de madeira e improvisavam cantigas em ritmo de marchinha. Só no século 19 a feste se popularizou e começou a tomar o formato conhecido atualmente (NASCIMENTO, 2017). 
Figura 1- Carnaval de Recife - Desfile do Galo da Madrugada.

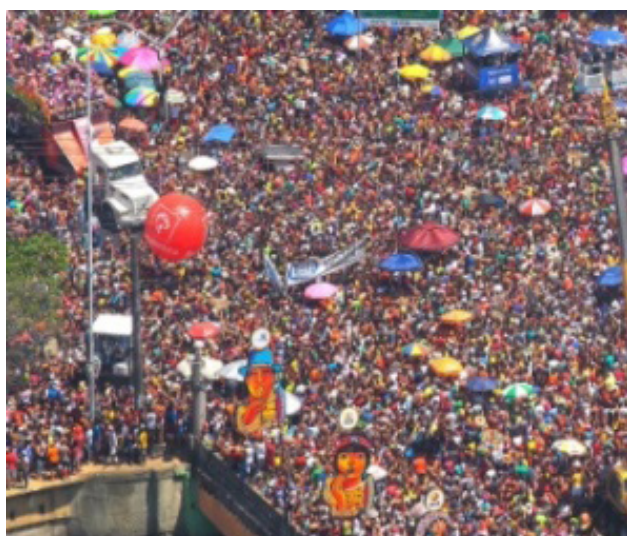

Fonte: Tavares (2017).
Figura 2 - Carnaval de Olinda - Desfile dos Bonecos Gigantes

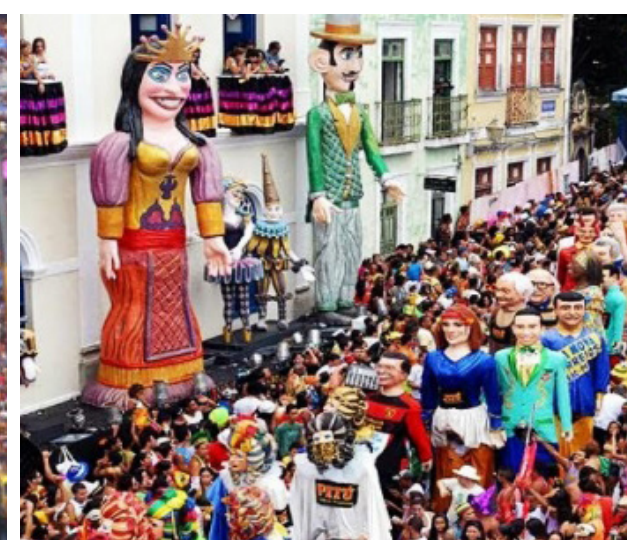

Fonte: Camarote... (2017).

Por volta de 1890, em busca de um ar mais divertido à comemoração, deu-se início ao uso de fantasias e adereços. Até 1930 as fantasias eram adaptadas ou ornadas de forma simples e sem muitos adereços, por conta do alto custo (BARROS, 2017).

Esse costume foi adotado nos bailes de carnaval brasileiros e continuou a se popularizar ao longo dos anos. Nos dias atuais, os foliões continuam abusando do humor e criatividade para fazer suas fantasias, porém, utilizando cada vez menos tecidos e peças, em consequência da sensação térmica elevada que o estado pernambucano proporciona durante os dias de folia.

Dubrovski (2010) salienta que a exposição ao ar livre pode afetar significativamente o grau de absorção à radiação ultravioleta (UV) e o uso de itens de proteção pessoal pode proporcionar uma redução substancial na dose de RUV recebido. Então, conforme os foliões optam por usar menos peças, o corpo tende a estar mais exposto à RUV, aumentando a dose de radiação recebida e absorvida pela pele.

\subsection{Riscos à Saúde Influenciados Pela Radiação Ultravioleta - RUV}

Em decorrência das perdas ocorridas na camada de ozônio, os raios ultravioletas têm aumentado progressivamente sua incidência sobre a terra. Segundo Freitas (2017) o Brasil tem 93\% de seu território localizado no Hemisfério Sul, contando com altos índices de RUV, classificados pelo (INPE) Instituto Nacional de Pesquisas Espaciais (2017), em raios UV-A (320 400nm), UV-B (280 - 320nm) e UV-C (100 - 280nm).

O (INCA) Instituto Nacional do Câncer José Alencar Gomes da Silva (2016) registra, a cada ano, 135 mil novos casos e o câncer de pele responde por $25 \%$ de todos os diagnósticos de câncer no Brasil. Na verdade, a maioria 
dos cânceres da pele está relacionada à exposição ao sol, por isso todo cuidado é pouco, principalmente no horário entre as $10 \mathrm{~h}$ e 16h, quando a radiação UVB é mais intensa, sendo esta a principal responsável pelo surgimento de doenças de pele.

A exposição da pele ao sol pode também trazer benefícios a saúde, como a obtenção de vitamina $D$, fortalecimento do sistema imunológico e bem-estar, podendo evitar o surgimento e ajudar no tratamento de doenças reumáticas, autoimunes, diabetes e alguns tipos de câncer (TOMAR..., 2011). A exposição recomendada por especialistas é de 15 a 30 minutos, antes das $10 \mathrm{~h}$ e após as $16 h$.

Uma das formas mais simples para proteção é o protetor solar em forma de creme, gel e spray, estes devem conter um bom fator de FPS (15-50) absorvendo com alta intensidade os raios UVA e UVB. Segundo a Sociedade Brasileira de Dermatologia (2013), os filtros ultravioletas, podem ser divididos em protetores inorgânicos ou físicos, à base de dióxido de titânio e óxido de zinco, se depositam na camada mais superficial da pele, refletindo as radiações incidentes; e protetores orgânicos ou químicos, que funcionam como uma espécie de "esponja" dos raios ultravioletas, transformando-os em calor.

O Fator de Proteção Solar (FPS) é o principal dado para quantificação da eficácia fotoprotetora de um filtro solar, seu método é baseado na determinação da Dose Eritematosa Mínima (DEM), definida como sendo a menor quantidade de energia necessária para o desencadeamento de eritema, em áreas de pele protegidas e não protegidas pelo produto. De acordo com a FDA e os protocolos internacionais, para determinar o FPS de protetores solares, a quantidade aplicada de produto é de $2 \mathrm{mg} / \mathrm{cm}^{2}$ (SCHALKA; REIS, 2011).

Os vestuários também podem ser mensurados quanto ao fator de proteção UV a partir da composição do tecido, percentual de fibras, estrutura, densidade, peso, cor, grau de humidade entres outros fatores. O fator de proteção ultravioleta nos tecidos é medido pelo grau de UPF, é o grau em que os tecidos podem apresentar em relação aos fatores de refletância ou absorvência dos raios UV.

\subsection{Proteção a Partir do Vestuário}

Recentemente tem se dado bastante foco ao uso de produtos com proteção UV, além dos acessórios, como cosméticos, maquiagens e roupas. Roupas feitas com tecidos especiais que passam por processos de acabamentos têxteis, onde são adicionados ao substrato têxtil nanopartículas, como de dióxido de titânio, que melhoram a absorção de radiação UV, são roupas que podem oferecer um alto fator UPF no vestuário (SUÁREZ, 2009). 
Para que efetivamente um tecido possa proteger a pele humana contra os raios nocivos, o substrato têxtil deve apresentar uma escala de UPF entre 15 e 50+. Onde 15 significa boa proteção e 50 + ficaria em excelente proteção.

Martins (2015) evidencia a ideia errada de que o vestuário, por si só, protege a pele da RUV, uma vez que, para que tal ocorra, devem ser levados em consideração alguns fatores como a estrutura do tecido, a sua densidade, a cor, a composição, a umidade, entre outros. Quando bem alinhados, esses fatores podem garantir a proteção UV nos vestuários, sendo assim insuficiente a simples ação do vestir, conforme as conclusões observadas na pesquisa de Fernandes (2003):

\begin{abstract}
As pesquisas científicas sobre a proteção da pele pelos produtos têxteis são relativamente recentes, o que leva a que poucas pessoas tenham conhecimento de que poderá não ser suficiente cobrir a pele com um tecido para estar protegido da RUV, uma vez que nem todos os tecidos têm o mesmo grau de proteção solar.
\end{abstract}

Desta forma, Martins (2015) ressalta que quando a radiação ultravioleta atinge o substrato têxtil, uma parte desta radiação é refletida, outra é absorvida e outra penetra no tecido e é transmitida de forma difusa para a pele, conforme pode ser observado na Figura 3.

Figura 3 - Reflexão da radiação em um substrato têxtil.

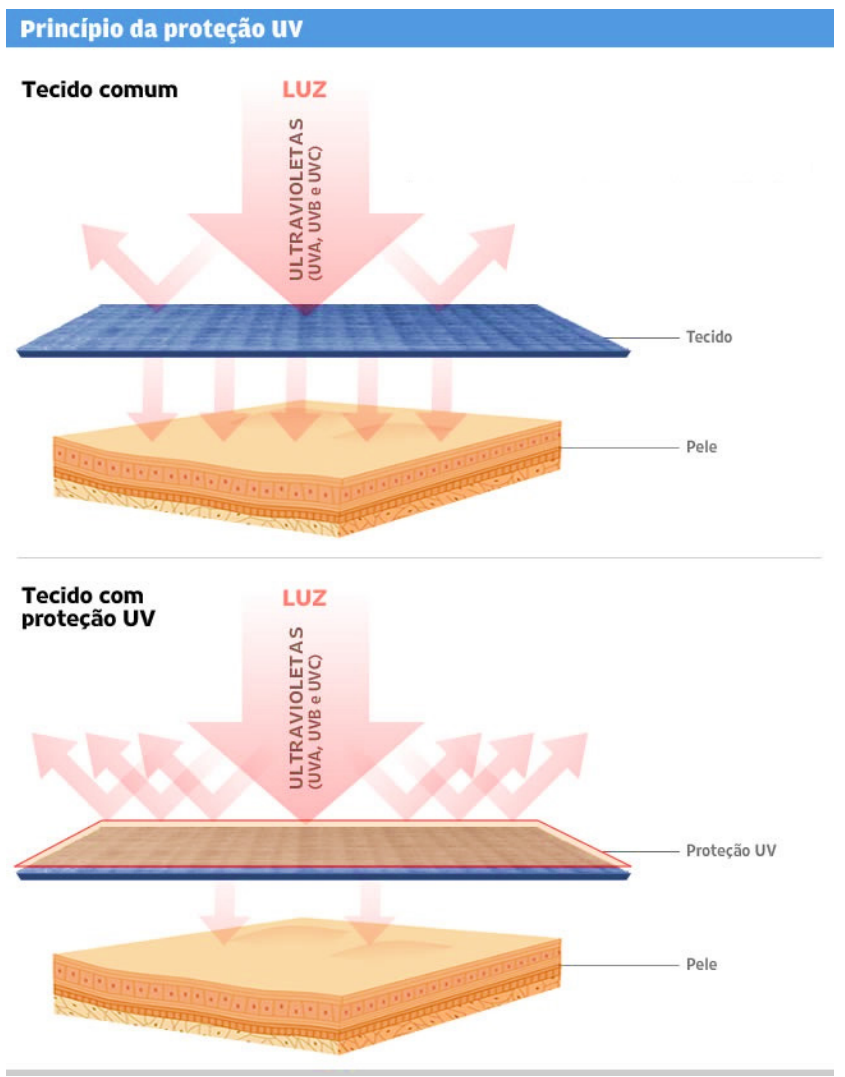

Fonte: Bruno Gallo (apud SAIBA..., 2010).

Projética, Londrina, v.10, n.3, p. 129-142, jul./dez. 2019 
Holme (2003) salienta que para que o tecido proteja a pele contra a RUV o componente de transmissão de radiação que atravessa o tecido tem que corresponder a uma percentagem inferior a $6 \%$ de UVA e 2,5\% de UVB para que em longo prazo não predisponha a pele ao câncer.

\section{4 Trajes de Carnaval}

O traje de carnaval é um tipo de vestimenta utilizada no período de festas e bailes carnavalescos que têm o intuito de simular, mascarar e fantasiar o seu portador em uma pessoa diferente da realidade.

"Desta forma, qualquer um pode vestir por diversão, por brincadeira, [...]" por emoção, por representação teatral ou no contexto do carnaval. Em qualquer das suas possibilidades, a fantasia geralmente tem um sentido de lazer e bastante orientada para o entretenimento (CONCEITO..., 2016).

Os trajes de carnaval mais comuns são as fantasias para os segmentos, adultos e infantis, como exemplo temos: as de passista de frevo, super-heróis e vilões, princesas, reis, figuras folks, bandas desenhadas, políticos, entre outras. Procuramos analisar a composição têxtil de algumas destas fantasias, a fim de compreender os benefícios, como o conforto e proteção ultravioleta, garantidos durante o seu uso no período de folia.

Figura 4 - Fantasia passistas de frevo.

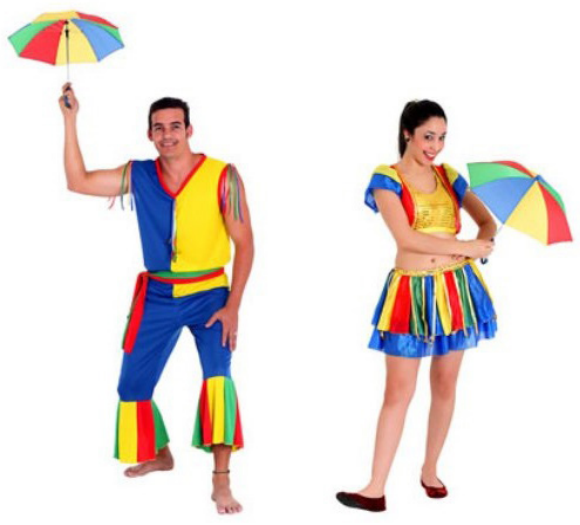

Fonte: Dicas de Mulher (2017). Composição: $100 \%$ poliéster, exceto adornos.
Figura 5 - Fantasia mulher maravilha.

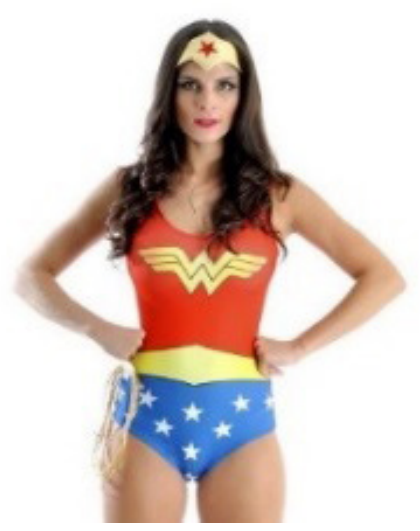

Fonte: ShopFácil (2017). Composição: 92\% poliéster, 8\% elastano.

Outro traje muito comum durante o carnaval brasileiro é o abadá, um vestuário que reflete uma espécie de uniformização e identificação dos foliões associados à um bloco. É uma camisa de malha sintética que passou a ser utilizada a partir de sua criação para o Bloco Eva no Carnaval de Salvador 1993 e nos anos seguintes, os demais blocos aderiram (CARNAXE, 2017). 
Figura 6 - Fantasia homem aranha (infantil)

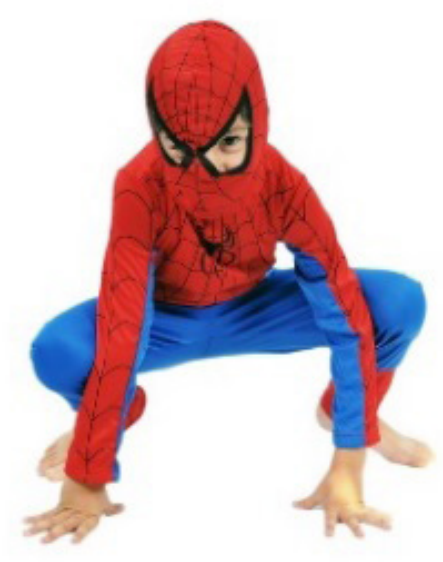

Fonte: Elo 7 (2017).

Composição: $100 \%$ poliéster, exceto adornos
Figura 7 - Fantasia branca de neve.

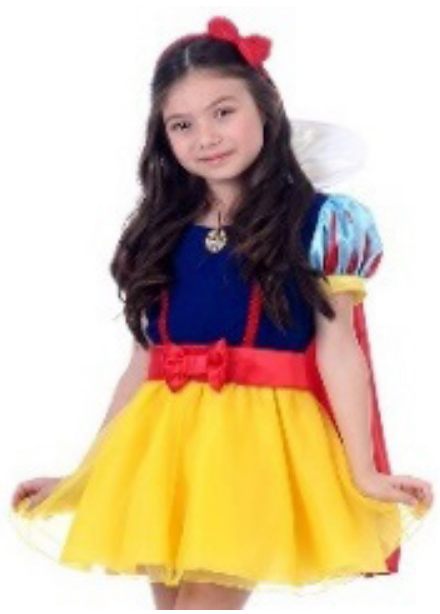

Fonte: Abrakadabra (2017).

Composição: 50\% poliéster, 30\% poliamida, 20\% acrílico; Mangas, gola e capa em $100 \%$ poliéster

Figura 8 - Abadá.
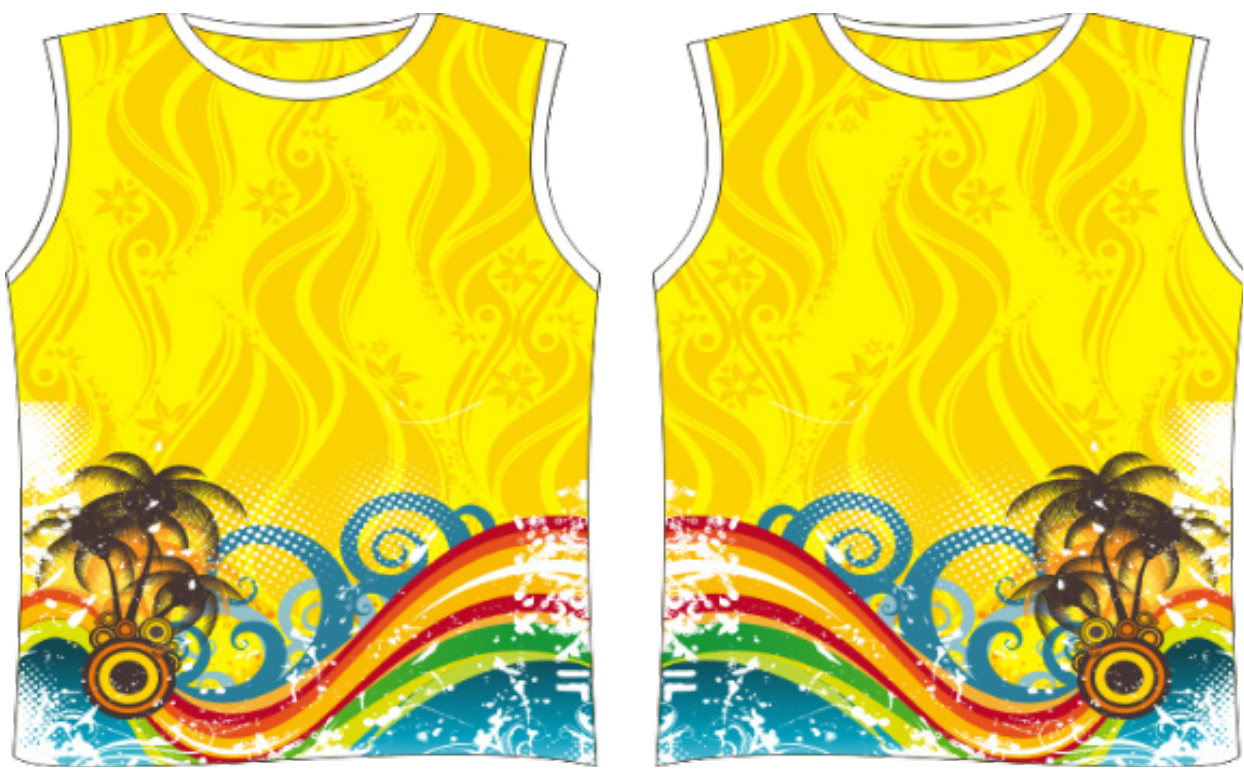

Fonte: Kamaleão (2017).

Com base nas pesquisas realizadas, notificou-se que a confecção das fantasias decorre, em sua maioria, a partir da utilização de fibras manufaturadas e materiais sintéticos. A fibra manufaturada sintética mais utilizada é o poliéster - PES. Esta fibra confere resistência, durabilidade, propriedade anti-rugas, versatilidade e baixo custo, quando comparado as fibras naturais (PEREIRA, 2017).

Os tecidos de poliéster também podem ser desenvolvidos em conjunto com outras fibras, caracterizando-os como tecidos mistos, aliando outras qualidades presentes em outras fibras, como pode ser visto abaixo. 
Algodão: A combinação entre algodão e poliéster pode ser obtida durante o processo de fiação, conferindo ao tecido um melhor caimento, excelente toque, aspecto diferenciado e melhor absorção de umidade, proporcionando maior praticidade e conforto (PEREIRA, 2017).

Elastano: O elastano, geralmente, entra em menor proporção na composição do tecido, sendo suficiente para evitar a deformação ao longo do tempo de uso e elasticidade, acomodando-se ao formato do corpo e oferecendo leveza a peça (BELOSO, 2016).

Poliamida: Caracterizam-se por possuírem alta resistência à tração e abrasão, elasticidade, tenacidade, boa capacidade de absorção, maciez, estabilidade térmica e regularidade, estas propriedades proporcionam uma grande variação de toques, caimentos e, consequentemente, aplicações (POLIAMIDA, 2014).

Acrílico: Sobressaem-se pelo aspecto lanoso e toque do mesmo tipo, pesam pouco, conservam bem o calor, resistem ao amassamento e tem ótima resistência a luz e a intempéries. Possuem alta capacidade para encolher de um lado e a solidez da forma de fibras encolhidas de outro (KUASNE, 2008).

Quando analisamos as fibras mencionadas quanto a sua resistência aos raios ultravioletas, nota-se que o poliéster oferece boa resistência aos raios UV, porém, quando mesclados com fibras de algodão há uma redução no aspecto de proteção ultravioleta. A adição do acrílico, elastano e poliamida é um outro fator de mescla de fibras que, neste caso, garante maior proteção, pois estes possuem elevada resistência as intempéries (luz e raios UV).

Em relação ao conforto, percebe-se que as fibras sintéticas não proporcionam sensações adequadas de conforto aos utilizadores. Estes tecidos não possuem características hidrofílicas, não absorvem o suor eliminado da pele e não conseguem transportar a umidade para o meio ambiente, proporcionando ao folião sensações de desconforto por apresentar corpo molhado, tecido encharcado, acúmulo de microorganismos, aparecimento e impregnação do odor.

\section{METODOLOGIA}

Os métodos de pesquisa utilizados partiram dos princípios de estudos de campo, de acordo com as definições de GIL (2008), este estudo busca o aprofundamento de uma realidade específica obtida por meio de observação direta das atividades do grupo estudado e de entrevistas com informantes para captar as explicações e interpretações que ocorrem naquela realidade. 
Desta forma, consistiu-se em observações diretas do comportamento de escolha da indumentária dos foliões durante o Carnaval de Recife e Olinda no ano de 2017, para angariar os dados houve a aplicação de questionários semiestruturados com 108 carnavalescos, ocorrendo a seleção da amostragem de forma aleatória. A descrição dos dados foi expressa de formas qualitativas e quantitativas por frequência absoluta (n) e relativa (\%).

\section{RESULTADOS E DISCUSSÕES}

Para relatar conhecimento dos foliões quanto a RUV e como esta os influencia durante o carnaval, foi realizada uma abordagem qualitativa e quantitativa de amostragem aleatória simples. Coletaram-se dados sobre identificação pessoal (idade, sexo e escolaridade), conhecimento dos danos à saúde relacionados à RUV, tempo de exposição solar, medidas preventivas à fotoexposição, ocorrência de doenças de pele e sobre as escolhas de roupas a serem utilizadas durante este período.

\subsection{Identificação Pessoal}

A população do estudo foi composta por foliões com idade entre 16 a 62 anos, sendo 44\% ( $n=48)$ homens e 56\% ( $n=60)$ mulheres, totalizando 108 entrevistados. A escolaridade teve variação desde o ensino fundamental a pósgraduação (doutorado), sendo o ensino superior mais mencionado por $70 \%$ $(n=76)$ dos carnavalescos.

\subsection{Conhecimentos e Influência da RUV Durante o Carnaval}

De início questionou-se o conhecimento aos riscos à saúde proveniente da exposição solar, onde, 97\% $(n=105)$ dos entrevistados declararam ter conhecimento e ainda assim o percentual de foliões que se exponham ao sol durante muito tempo foi de $63 \%(n=68)$, num intervalo de 30 minutos a 08 horas, as horas mencionadas podem ser visualizadas no gráfico 01.

Gráfico 1 - Tempo de exposição solar dos foliões durante o carnaval.

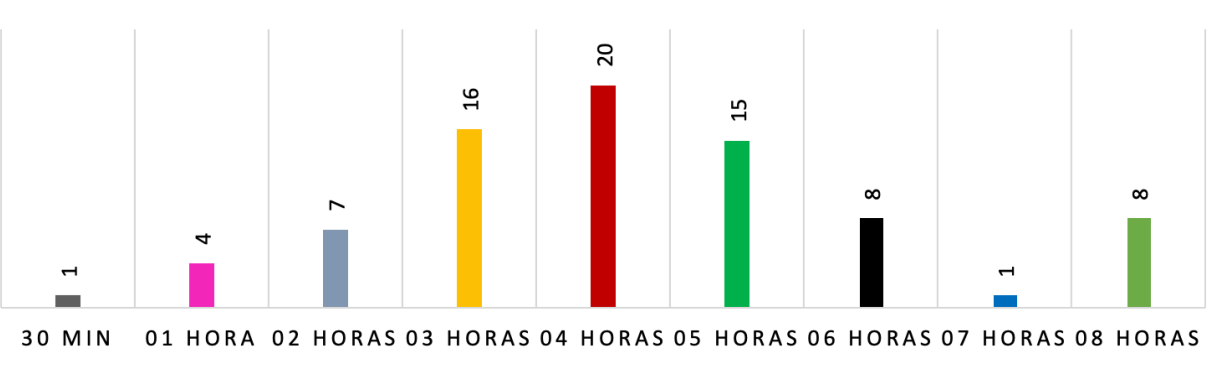

Fonte: Autores. 
O alto percentual se eleva também no aspecto de acompanhamento de blocos e/ou troças carnavalescas, por $69 \%(n=44)$ dos entrevistados, o que influi no entendimento à excessiva exposição solar.

\subsection{Medidas Preventivas}

Uma das formas mais citadas de proteção durante o carnaval foi o protetor solar, por $82 \%(n=89)$ dos entrevistados. Porém $34 \%(n=37)$ dos carnavalescos só o aplicam uma vez durante o dia, geralmente antes de sair de casa. É sabido que é necessária a reposição do fotoprotetor a cada 2 horas para ser considerada uma medida preventiva eficiente. Desta forma, a quantidade de aplicações não se faz necessária para atingir o fator de proteção solar (FPS), normalmente descrito na embalagem do produto.

Além da menção do creme de proteção solar, foram mencionados uso de coberturas (chapéus e bonés), óculos de sol e roupas com proteção UV, onde $5 \%(n=5)$ dos entrevistados disseram não se proteger da fotoexposição, conforme pode ser visualizado no gráfico 2 .

Gráfico 2 - Medidas preventivas dos foliões durante o carnaval.

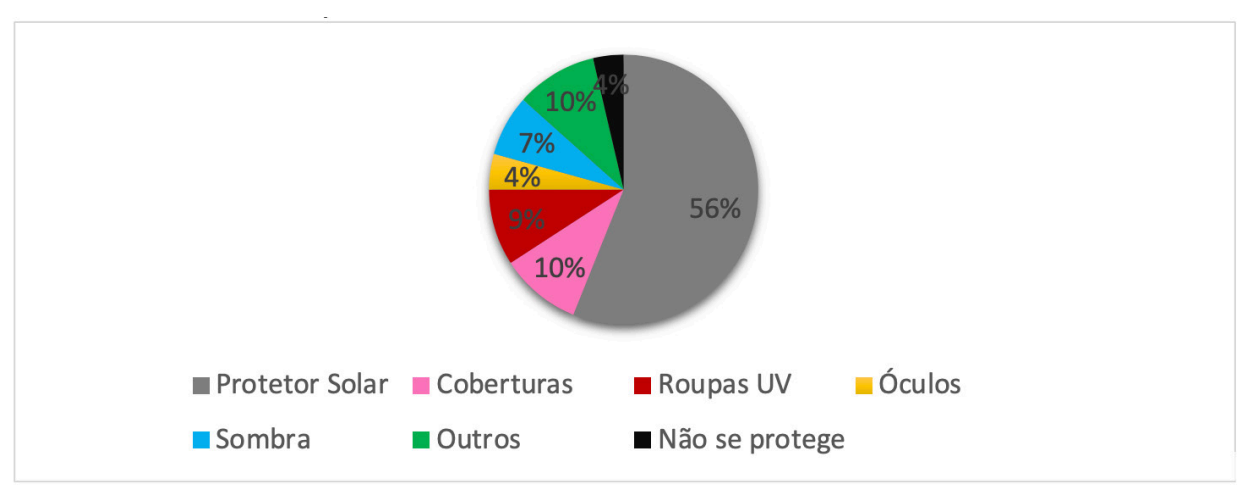

Fonte: Autores.

Pode-se perceber também que a radiação ultravioleta não influencia os foliões nas escolhas de roupas ou fantasias a serem utilizadas durante os dias de folia, já que $83 \%(n=90)$ relataram não pensar numa vestimenta que traga proteção. E quando questionados sobre a existência do costume de molhar-se e permanecer exposto ao sol, $43 \%(n=47)$ dos entrevistaram afirmaram que possuem este hábito, sendo um fator preocupante, já que Das (2010) ressalta que a UPF do vestuário molhado é significativamente menor do que o vestuário de mesma medida no estado seco, resultando numa redução de proteção e aumento de risco à saúde do folião. 


\subsection{Ocorrência de Doenças}

De acordo com Monteiro (2016), durante o verão e carnaval se elevam os riscos de algumas doenças de pele, como as manchas, sardas, micoses, brotoejas e acne solar, fazendo menção também aos riscos de agravamento do melasma devido ao aumento de temperatura e incidência da radiação solar.

Outro possível risco são as reações alérgicas a determinados tipos de tecido, por este motivo o Inmetro (2016) ofertou dicas simples que garantem a segurança do folião que consistem em conferir as etiquetas dos produtos.

Todas as fantasias devem conter na etiqueta as seguintes informações obrigatórias em português: dados do fabricante ou importador, CNPJ, país de origem, composição têxtil, cuidados de conservação e indicação de tamanho. Esses dados ajudam, por exemplo, a evitar possíveis reações alérgicas a determinados tipos de tecido (INMETRO, 2016).

Nenhum caso de doença de pele relacionado ao carnaval foi referido por $94 \%(n=101)$ dos entrevistados. Porém é válido ressaltar que as doenças de pele tendem a ser silenciosas e possuem efeito acumulativo, podendo não serem evidenciadas no primeiro ano de carnaval, mas é necessário ter precaução para os outros anos que estão por vir. Dentre os $6 \%(n=7)$ entrevistados que admitiram a existência de alguma doença, estas foram voltadas para os efeitos imediatos da exposição como à insolação, vermelhidão, manchas e queimaduras solares.

\section{CONSIDERAC̣̃̃ES FINAIS}

Pode-se constatar que embora os entrevistados relatem ter conhecimento quanto aos riscos para a saúde provocados pela radiação ultravioleta - RUV, notificou-se que os foliões ainda se expõem ao sol por longos períodos de tempo durante os dias de carnaval sem a proteção necessária de FPS e de UPF. Desta forma, evidenciou-se a ausência de preocupação relacionada a medidas preventivas à RUV por parte dos foliões, onde a sensação térmica elevada durante este período os influencia na escolha das fantasias e vestuário, pois os carnavalescos buscaram uma redução de peças, apostaram em roupas curtas e decotadas, ou seja, muita exposição do corpo e pouca aplicação de fotoprotetor, afetando significativamente o grau de absorção de raios UV absorvidos pela pele.

O estudo realizado permitiu compreender como a composição têxtil dos trajes de carnaval influem na proteção UV de seus utilizadores. E que, apesar do poliéster oferecer boa resistência aos raios UV e estar presente na maioria das 
vestimentas analisadas, estes devem ser regulamentados com fator mínimo de UPF 15 para garantir um bom fator de proteção. Diante do exposto, é válido ressaltar a importância do índice de UPF do tecido, a fim de prevenir as doenças cutâneas, especificamente o câncer de pele, possibilitando o bem-estar dos foliões durante os dias de carnaval.

Sendo assim, faz-se necessário um acréscimo de produtos têxteis que aliem a diversão do carnaval à proteção, além de acréscimo de noticiais e campanhas que circundam o assunto, alertando a população ainda mais a respeito dos riscos e formas de prevenção à exposição excessiva, para que os carnavalescos garantam mais dias de folia com conforto e bem-estar. As indústrias e empresas de confecções devem apostar em novos tecidos (mistos), novas modelagens e novos modelos para que possam ser desenvolvidos trajes de carnaval que possam atuar como escudo de proteção ultravioleta dos foliões nos dias de diversão sem esquecer o conforto destes trajes. Pois, há um grupo emergente de consumidores conscientes e exigentes que vem buscando estes novos produtos.

\section{REFERÊNCIAS}

ABRAKADABRA. Fantasia branca de neve. Disponível em: http://www. abrakadabra.com.br/. Acesso em: 25 set. 2017.

BARBOSA, Ludmyla. História do carnaval. Mooca, SP: KERDNA Produção Editorial, 2017.

BARROS, Jussara de. Fantasias do carnaval. Disponível em: https:// brasilescola.uol.com.br/carnaval/fantasias.htm. Acesso em: 7 jul. 2017.

BELOSO, Thais. As inúmeras vantagens do elastano. 2016. Disponível em: http://www.audaces.com/as-inumeras-vantagens-do-elastano/. Acesso em: 31 ago. 2017.

CAMAROTE Olinda 2017 anima Festa de Momo. Grupo WSCOM de Comunicação, Olinda, PE, 21 fev. 2017. Entretenimento. Disponível em: http:// saiadarota.com/. Acesso em: 25 set. 2017.

CARNAXE. Abadás: Resgate da trajetória carnavalesca. Disponível em: http:// www.carnaxe.com.br/abadas/historia2.htm. Acesso em: 1 set. 2017.

CONCEITO e definição do traje. In: WIKCIONÁRIO Conceitos. 2016. Disponível em: https://dicionarioconceitos.blogspot.com.br/2016/05/ conceito-e-definicao-do-traje.html. Acesso em: 1 ago. 2017.

DAS, Biswa Ranjan. UV radiation protective clothing. The Open Textile Journal, New Delhi, n. 3, p. 14-21, 2010. Disponível em: https://pdfs.semanticscholar. org/5601/7c3211a82cf0cf839c97fcca1fc5f680004c.pdf. Acesso em: 1 ago. 2017. 
DICAS DE MULHER. Fantasias fáceis de fazer. Passista de frevo. Disponível em: http://dicasdamulher.com.br/. Acesso em: 25 set. 2017.

DUBROVSKI, Polona Dobnik. Woven fabrics and ultraviolet protection. In: DUBROVSKI, Polona Dobnik (ed.). Woven fabric engineering. Rijka, CRO: In Tech, 2010. p. 273-296.

ELO 7. Fantasia infantil Homem Aranha. Disponível em: https://www.elo7.com. br/lista/fantasia-infantil-homem-aranha?nav=sb. Acesso em: 25 set. 2017.

FERNANDES, Luís Filipe Folgado Carneiro Leite. Determinação da protecção solar de tecidos em função da estrutura, cor e humidade. 2003. Dissertação (Mestrado em Design e Marketing) - Departamento de Engenharia Têxtil, Universidade do Minho, Guimarães, Portugal, 2003. Disponível em: https:// repositorium.sdum.uminho.pt/handle/1822/836. Acesso em: 28 jul. 2017.

FREITAS, Eduardo de. Localização do Brasil no mundo. Disponível em: http:// brasilescola.uol.com.br/. Acesso em: 19 jun. 2017.

GIL, Antonio Carlos. Métodos e técnicas de pesquisa social. 6. ed. São Paulo: Atlas, 2008.

HOLME, I. UV absorbers for protection and performance. International Dyer, Hannover, v. 4, n. 13, p. 9-10, 2003.

http://historia-do-carnaval.info/fale-conosco.html. Acesso em: 7 jul. 2017.

INMETRO. Dicas para um carnaval seguro. 2016. Disponível em: http://www. inmetro.gov.br/noticias/. Acesso em: 30 ago. 2017.

INSTITUTO NACIONAL DE CÂNCER JOSÉ ALENCAR GOMES DA SILVA INCA. Incidência de câncer no Brasil: estimativa 2016. Disponível em: http:// www.inca.gov.br/estimativa/2016/index.asp?ID=2. Acesso em 13 jul. 2017.

INSTITUTO NACIONAL DE PESQUISAS ESPACIAIS - INPE. Índice ultravioleta. Disponível em: http://www.inpe.br/. Acesso em: 28 jul. 2017.

KAMALEÃO. Modelos de abadá. Disponível em: http://kamaleao.com/. Acesso em: 25 set. 2017.

KUASNE, Ângela. Fibras têxteis. 2008. Disponível em: https://wiki.ifsc.edu.br/ mediawiki/images/8/88/Apostila_fibras.pdf. Acesso em: 31 ago. 2017.

MARTINS, Etienne Amorim Albino da Silva. O estudo da aplicação de acabamentos funcionais de barreira UV em fibras previamente ativadas por plasma. 2015. Tese (Doutoramento em Engenharia Têxtil) - Departamento de Engenharia Têxtil, Universidade do Minho, Guimarães, PortugaL, 2015. Disponível em: https://repositorium.sdum.uminho.pt > bitstream > Tese_ Etienne Amorim Al... Acesso em: 25 set. 2017.

MONTEIRO, Lilian. Veja quais são os principais cuidados com a pele no carnaval e no verão. 2016. Disponível em: http://www.uai.com.br/. Acesso em: 7 jul. 2017. 
NASCIMENTO, Anamaria. Caindo na folia muito antes do frevo. 2017. Disponível em: http://www.impresso.diariodepernambuco.com.br/. Acesso em: 5 maio 2017.

PEREIRA, Gislaine de Souza. Introdução à tecnologia têxtil. Disponível em: https://wiki.ifsc.edu.br/mediawiki/images/7/7d/Apostila_tecnologia.pdf. Acesso em: 31 ago. 2017.

POLIAMIDA (PA). São Leopoldo, RS: Plastfera Indústria de Plásticos Técnicos Eireli, 2014. Disponível em: https://www.plastfera.com/produtos/materiaprima/poliamida-pa-/. Acesso em: 31 ago. 2017.

SAIBA como funcionam os tecidos com proteção contra raios UV. Brasil Online (BOL), São Paulo, 24 fev. 2010. Bol Noticias. Disponível em: https://noticias. bol.uol.com.br/brasil/2010/02/24/saiba-como-funcionam-os-tecidos-comprotecao-contra-raios-uv.jhtm. Acesso em: 25 set. 2017.

SCHALKA Sergio; REIS, Vitor Manoel Silva dos. Fator de proteção solar: significado e controvérsias. Anais Brasileiros de Dermatologia, Rio de Janeiro, v. 86, n. 3, p. 507-515, maio/jun. 2011.

SHOPFÁCIL. Fantasia mulher maravilha. Disponível em: http://www.shopfacil. com.br/. Acesso em: 25 set. 2017.

SOCIEDADE BRASILEIRA DE DERMATOLOGIA - SBD. 2013. Consenso brasileiro de fotoproteção. Disponível em: www.sbd.org.br. Acesso em: 8 maio 2017.

SUÁREZ, Hector; ACOSTA, Delicia Ester; CADENA, Carlos Alberto. Caracterización de diferentes tejidos como protectores solares. Revista AVERMA, San Miguel, v. 13, p. 41 - 51, 2009.

TAVARES, Fabiana. Carnaval Recife - Olinda. Niterói - RJ: Saia da Rota, 2017.

TAVARES, Fabiana. Carnaval Recife - Olinda. Saia da rota. Disponível em: http://saiadarota.com/. Acesso em: 25 set. 2017.

TOMAR sol é fundamental para o corpo obter vitamina $D$, explica especialista. G1, São Paulo, 16 mar. 2011. Notícia. Disponível em: http://g1.globo.com/ bemestar/noticia/2011/03/tomar-sol-e-fundamental-para-o-corpo-obtervitamina-d-explica-especialista.html. Acesso em: 28 jul. 2017. 